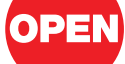

SUBJECT AREAS:

NUCLEAR PHYSICS

ENERGY

APPLIED PHYSICS

EARTH SCIENCES

Received

19 June 2012

Accepted

28 June 2012

Published

12 July 2012

Correspondence and requests for materials should be addressed to

S.T. (tokonami@cc. hirosaki-u.ac.jp)

\section{Thyroid doses for evacuees from the Fukushima nuclear accident}

\author{
Shinji Tokonami ${ }^{1}$, Masahiro Hosoda², Suminori Akiba ${ }^{3}$, Atsuyuki Sorimachi' , Ikuo Kashiwakura' ${ }^{1,2}$ \\ \& Mikhail Balonov ${ }^{4}$
}

'Department of Radiation Physics, Institute of Radiation Emergency Medicine, Hirosaki University, Hirosaki City, Aomori 036-8564, Japan, ${ }^{2}$ Department of Radiological Life Sciences, Graduate School of Health Sciences, Hirosaki University, Hirosaki City, Aomori 036-8564, Japan, ${ }^{3}$ Department of Epidemiology and Preventive Medicine, Graduate School of Medical and Dental Sciences, Kagoshima University, Kagoshima City, Kagoshima 890-8544, Japan, ${ }^{4}$ Protection Laboratory, Institute of Radiation Hygiene, Mira St 8, St. Petersburg 197101, Russia.

A primary health concern among residents and evacuees in affected areas immediately after a nuclear accident is the internal exposure of the thyroid to radioiodine, particularly I-131, and subsequent thyroid cancer risk. In Japan, the natural disasters of the earthquake and tsunami in March 2011 destroyed an important function of the Fukushima Daiichi Nuclear Power Plant (F1-NPP) and a large amount of radioactive material was released to the environment. Here we report for the first time extensive measurements of the exposure to I-131 revealing I-131 activity in the thyroid of 46 out of the 62 residents and evacuees measured. The median thyroid equivalent dose was estimated to be $4.2 \mathrm{mSv}$ and $3.5 \mathrm{mSv}$ for children and adults, respectively, much smaller than the mean thyroid dose in the Chernobyl accident (490 $\mathrm{mSv}$ in evacuees). Maximum thyroid doses for children and adults were $23 \mathrm{mSv}$ and $33 \mathrm{mSv}$, respectively.

n $11^{\text {th }}$ March 2011, a 9.0 magnitude earthquake and subsequent tsunami led to major problems in the stabilization of nuclear power reactors in $\mathrm{F} 1-\mathrm{NPP}^{1-3}$. Following plural hydrogen explosions and fire damage to the facilities, a large amount of radioactive material was released to the environment ${ }^{4,5}$. Radiation monitoring data ${ }^{6}$ in Iitate near Tsushima District and mathematical simulations based on dosimetry data $^{7,8}$ indicate that a highly radioactive plume arrived at around 1 p.m. on March $15^{\text {th }}$. Note also that it started to rain at around 5 p.m. on March $15^{\text {th }}$. Namie Town and Iitate Village, located to the northwest of F1-NPP, are among the municipalities heavily contaminated by radioactive plumes from the crippled plant ${ }^{9}$. Concern over exposure to radioactive materials prompted the local health authorities to conduct a preliminary screening test for activity in the thyroid of children in Iwaki City, Kawamata Town and Iitate Village. However further investigations were needed to fully understand the situation.

When considering the release of radioactive materials to the air, special attention must be paid to volatile elements including iodine (I-131, I-132, I-133), cesium (Cs-134, Cs-136, Cs-137) and tellurium (Te-132), as well as inert gases such as xenon $(\mathrm{Xe}-133)^{10,11}$. A primary concern among residents and evacuees, staying in heavily contaminated areas in the early days after the accident, is the internal thyroid exposure of children to radioiodine and consequent thyroid cancer risk. Once taken into the human body, 10-30\% of radioiodine accumulates in the thyroid $^{12}$. After the Chernobyl accident, thyroid cancer increased among children who had internal exposure to radioiodine through milk intake ${ }^{13}$. The thyroid weight of an infant is much smaller and milk consumption per unit mass is much larger compared with an adult. However, in Fukushima, internal exposure through ingestion is considered negligible since local products including milk were not given to children ${ }^{14}$. Therefore, inhalation is considered to be the most probable pathway of intake in this F1-NPP accident.

According to the survey by Japan Broadcasting Corporation (NHK), more than 6,000 residents including infants evacuated from coastal areas and stayed in Namie Town, Tsushima District, for several days from March $12^{\text {th }}$ to $15^{\text {th }}$. The system for Prediction of Environmental Emergency Dose Information (SPEEDI) estimated that the thyroid dose for 1-year-old infants spending time outdoors in various areas of Tsushima District during the period between 6:00 on March $12^{\text {th }}$ to 0:00 on April $6^{\text {th }}$ may range from $100 \mathrm{mSv}$ to $500 \mathrm{mSv}$ as shown in (Fig. 1$)^{15}$. On $23^{\text {rd }}$ March, 2011, based on the estimated thyroid dose among 1-year-old infants obtained from SPEEDI, an advisory panel for the Nuclear Safety Commission (NSC) of Japan recommended evaluation of the internal thyroid exposure to I-131 for children in high-radiation dose areas. In response to the recommendation, local 


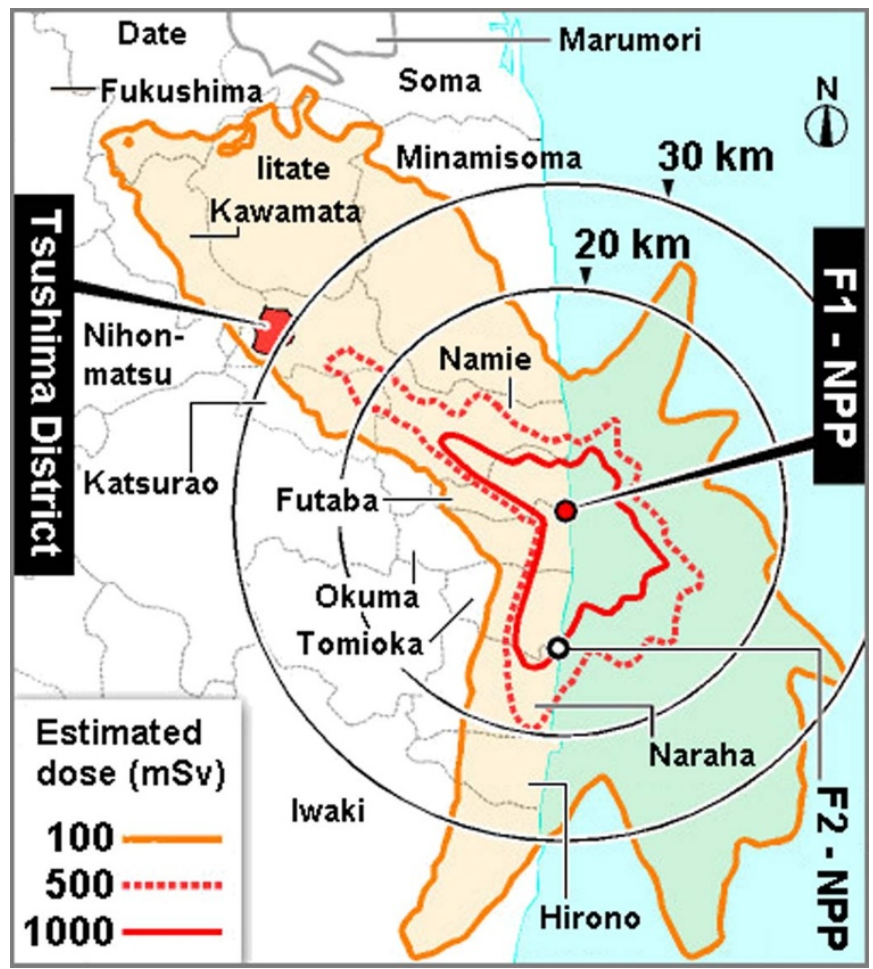

Figure $1 \mid$ Thyroid dose contour map. The dose for one-year-old infants in the areas surrounding the reactor was estimated by SPEEDI (System for Prediction of Environmental Emergency Dose Information $)^{15}$. Tsushima District of Namie Town is located within the $30-\mathrm{km}$-radius zone around the reactor. The figure was provided by the Asahi Shinbun and modified.

health authorities measured the activity in the thyroid of 1,149 children under the age of 15 in Iwaki City, Kawamata Town and Iitate Village from March $24^{\text {th }}$ to $30^{\text {th }}{ }^{14}$. For this measurement a 1-inch $\times$ 1-inch $\mathrm{NaI}(\mathrm{Tl})$ scintillation survey meter was placed on the neck of examinees. In this examination, $1 \%$ of children exceeded $0.04 \mu \mathrm{Sv}$ $\mathrm{h}^{-1}$. The maximum dose rate was $0.07 \mu \mathrm{Sv} \mathrm{h}^{-1}$, which was considered to be equivalent to a thyroid dose of $35 \mathrm{mSv}^{14}$. Since this examination could only be regarded as a screening test, more detailed measurements were needed. Although the NSC pointed out the need for further investigation, no further examinations were carried out by the local authorities at the time. It should be noted that I-131 has a half-life of 8 days and therefore it is necessary to make activity measurements of I-131 in the thyroid rapidly.

Here we report for the first time extensive measurements of the exposure to I-131 revealing I-131 activity in the thyroid of 46 out of the 62 residents and evacuees measured.
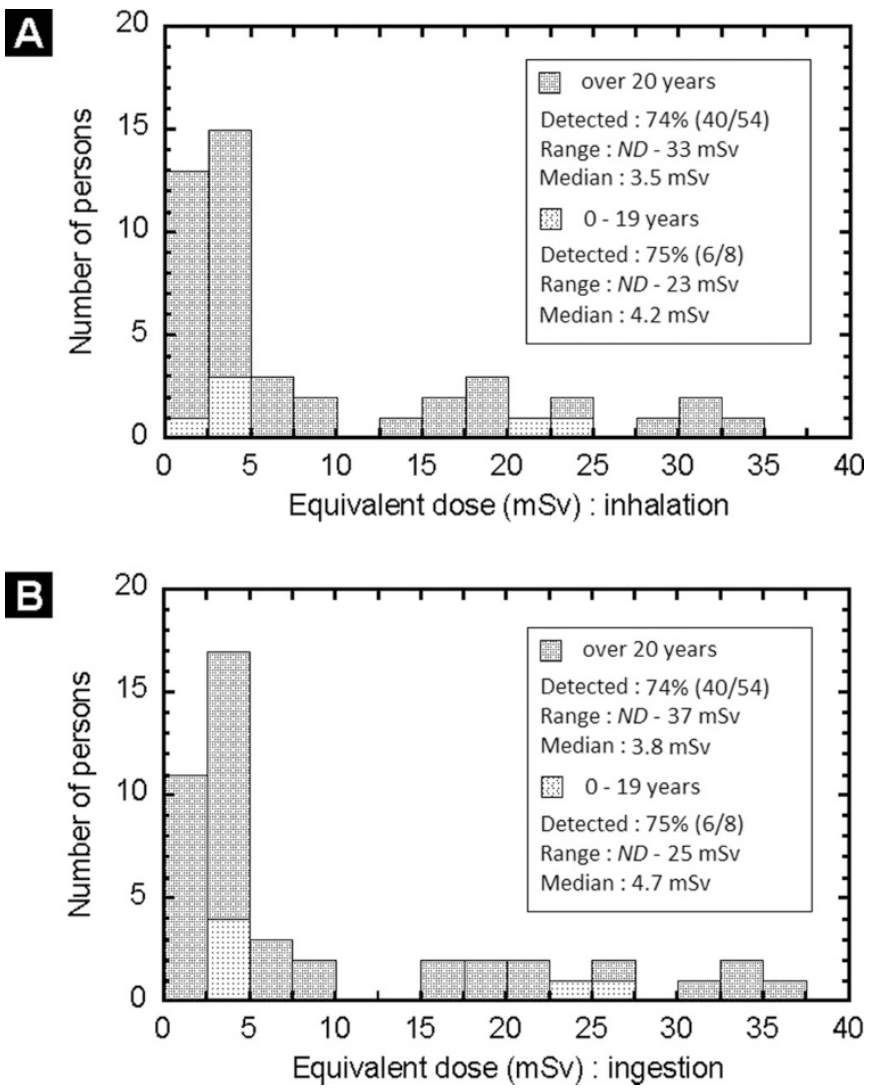

Figure $2 \mid$ Distribution of measured persons by thyroid equivalent dose from inhalation (A) and ingestion (B) of I-131. Each dose was calculated according to I-131 activity in the thyroid and the age-dependent equivalent thyroid dose coefficient ${ }^{16,17}$.

\section{Results}

We conducted I-131 activity measurements in the thyroid of residents and evacuees during the period from April $12^{\text {th }}$ to $16^{\text {th }}$, placing a 3-inch $\times 3$-inch $\mathrm{NaI}(\mathrm{Tl})$ scintillation spectrometer at the neck of examinees. The study was approved by the Committee of Medical Ethics of Hirosaki University Graduate School of Medicine (Hirosaki, Japan). In total, 62 people aged from 0 to 83 years old (of which accurate information on age was unavailable for eight people) underwent the measurement with informed consent. Net thyroid and background count rates were determined from the detected gamma spectra measured for the most conservative dose assessment, we used thyroid equivalent dose coefficients for iodine in elemental form, as given by ICRP Publication $71^{16}$, and the thyroid uptake factor equal to 0.3 . We found detectable I-131 activity in 39 of the 45 people evacuated from coastal areas, and in 7 of the 17

Table 1 | Number of persons by group, range of thyroid activity measured on April 12 to $16^{\text {th }}, 2011$, and equivalent thyroid dose Age group Number of persons $\mathrm{I}-131$ thyroid activity range $(\mathrm{kBq})$ Thyroid dose range $(\mathrm{mSv})$ : inhalation Thyroid dose range (mSv) : ingestion

\begin{tabular}{lrccc}
\hline $0-9$ & 5 & N.D. -0.017 & N.D. -21 & N.D. -24 \\
$10-19$ & 3 & $0.090-0.54$ & $3.8-23$ & $4.2-25$ \\
$20-29$ & 9 & N.D. -0.59 & N.D. -16 & N.D. -17 \\
$30-39$ & 6 & N.D. -0.17 & N.D. -4.4 & N.D. -4.9 \\
$40-49$ & 4 & N.D. -1.5 & N.D. -33 & N.D. -37 \\
$50-59$ & 10 & N.D. -1.1 & N.D. -5.3 & N.D. -5.8 \\
$60-69$ & 12 & N.D. -0.20 & $2.3-31$ & $2.5-34$ \\
$70-79$ & 3 & $0.090-1.5$ & N.D. -19 & N.D. -21 \\
$80+$ & 2 & N.D. -0.70 & N.D. -28 & N.D. -30 \\
Unknown & 8 & N.D. -1.4 &
\end{tabular}


Table 2 | Estimation of possible thyroid equivalent dose for children using the assumed maximum atmospheric l-131 concentration

\begin{tabular}{|c|c|c|c|c|}
\hline Age & Breathing volume per $4 \mathrm{~h}\left(\mathrm{~m}^{3}\right)$ & Total $1-131$ intake (kBq) & Thyroid dose coefficient ${ }^{16}\left(\mathrm{mSv} \cdot \mathrm{kBq}^{-1}\right)$ & Thyroid dose (mSv) \\
\hline 3 months & 0.48 & $10.9 \pm 0.9$ & 3.3 & $36 \pm 3$ \\
\hline 1 year & 0.86 & $19.7 \pm 1.6$ & 3.2 & $63 \pm 5$ \\
\hline 5 years & 1.45 & $33.4 \pm 2.6$ & 1.9 & $63 \pm 5$ \\
\hline 15 years & 3.35 & $76.9 \pm 6.1$ & 0.6 & $48 \pm 4$ \\
\hline
\end{tabular}

residents in Tsushima District. Figure 2 illustrates the distribution of thyroid equivalent dose in children and adults assessed using the equivalent dose coefficient by inhalation and by ingestion for their comparison $^{16,17}$. Table 1 summarizes the range of I-131 activities and thyroid doses according to age. Thyroid equivalent doses by inhalation ranged from none detected (N.D.) to $33 \mathrm{mSv}$. The median thyroid equivalent dose for children (under 20 years of age) and adults was 4.2 and $3.5 \mathrm{mSv}$, respectively.

\section{Discussion}

The thyroid equivalent doses assessed in this study were much smaller than the mean thyroid dose in the Chernobyl accident (which was $490 \mathrm{mSv}$ in evacuees) ${ }^{13}$. Thyroid equivalent doses assessed assuming an ingestion pathway were similar to those found for inhalation. Even when either of the two intake pathways or their combination was assumed, no dose exceeded $50 \mathrm{mSv}$.

Some children were known to have stayed in heavily contaminated areas from March $11^{\text {th }}$ to $18^{\text {th }}$. As the most conservative scenario, we estimated the thyroid dose to children, using the atmospheric I-131 concentration assessed from the thyroid measurements of adults. As mentioned earlier, we considered that the rainfall on March $15^{\text {th }}$ resulted in deposition of ambient radioactive materials on the ground and subsequent less possibilities to inhale them. The maximum I-131 activity detected in the thyroid of an adult was $1.5 \mathrm{kBq}$. Assuming the inhalation exposure took place for 4 hours on the afternoon of March $15^{\text {th }}$ (see above), we estimated that this person could inhale as much as $85 \mathrm{kBq}$ of I-131. Using the thyroid activity and breathing rate $^{16}$, the maximum atmospheric I-131 concentration was estimated to be $23 \mathrm{kBq} \mathrm{m}^{-3}$. In our data analysis, we did not consider I-132 exposure due to lack of information.

Using the maximum atmospheric concentration, the thyroid dose for different age groups from inhalation of I-131 was calculated for children as shown in Table 2. In this estimation the dose for 1-, 5- and 10 -year-old children could exceed $50 \mathrm{mSv}$. If children in this age range remained in Tsushima District after the radioactive plume arrived in the afternoon of March $15^{\text {th }}$, they might have experienced further exposure to I-131. Since the maximum I-131 concentration was obtained from an adult's activity, inhaled activity by infants could be less because they usually stay indoors in cold winter weather.

Therefore the findings suggest that it is necessary to identify children who were outdoors during the period when the highly radioactive plume arrived, and to periodically examine them. From both radiological and risk-assessment aspects, it is important to conduct these investigations to better understand the initial exposure conditions following the accident.

\section{Methods}

Evaluation of thyroid equivalent dose. We made I-131 activity measurements in the thyroid for examinees from two different areas. Seventeen were residents in Tsushima District of Namie Town, heavily contaminated with radioactive materials released from the crippled plant. Forty five were those evacuated from coastal areas including Minami-soma City located to the north of Fukushima Dai-ichi Nuclear Power Plant. We measured activity in the thyroid during the period from April $12^{\text {th }}$ to $16^{\text {th }}, 2011$, using a 3-inch $\times 3$-inch $\mathrm{NaI}(\mathrm{Tl})$ scintillation spectrometer (JSM-112, Hitachi Aloka Medical, Ltd., Tokyo). We wrapped the detection head with plastic foil and cleaned the neck with alcohol wipes so as to avoid radioactive contamination. We then placed the detection head on the cleaned part of the neck and started the measurement. After
$300 \mathrm{sec}$, we obtained a gamma-ray pulse height spectrum. Using the I-131 counting data, we calculated the activity by the equation (1):

$$
A_{\mathrm{T}}=\frac{n_{\mathrm{t}}-n_{\mathrm{b}}}{\eta}
$$

Where $A_{\mathrm{T}}$ is the I-131 activity in the thyroid $(\mathrm{Bq}) ; n_{\mathrm{t}}$ is the net count rate in the identified region of the examinee (counts per second, cps), $n_{\mathrm{b}}$ is the background net count rate (cps), and $\eta$ is counting efficiency of the equipment (cps/Bq). We calculated these two net count rates by the Covell method ${ }^{18}$. We estimated a minimum detectable count rate $(N)$ with the background net count rate calculated according to Covell and equation (2):

$$
N=3 \sqrt{2 n_{\mathrm{b}}}
$$

We used the counting efficiency obtained from experiments with a neck phantom and a thyroid phantom filled with I-131 solution ${ }^{19}$. The distance between the neck and thyroid phantoms was $1 \mathrm{~cm}$. Ishikawa and Uchiyama prepared three thyroid phantoms with different volumes, i.e., 4, 12 and $16 \mathrm{ml}$. We used conservative counting efficiencies of $4 \mathrm{ml}$ for young children $\left(3.49 \times 10^{-2} \mathrm{cps} / \mathrm{Bq}\right)$ and $12 \mathrm{ml}$ for adults $\left(3.96 \times 10^{-2} \mathrm{cps} / \mathrm{Bq}\right)^{19}$. We calculated the thyroid equivalent dose from I-131 activity in the thyroid obtained by the measurement as follows:

$$
D_{\mathrm{T}, 0}=\frac{A_{\mathrm{T}}}{(0.5)^{t / T_{\mathrm{eff}}}} \cdot f \cdot i^{-1}
$$

Where $D_{\mathrm{T}, 0}$ is the thyroid equivalent dose $(\mathrm{mSv})$ assuming that they inhaled I-131 on March $15^{\text {th }}, t$ is the elapsed time between March $15^{\text {th }}$ and the measured date, $T_{\text {eff }}$ is the effective half-life of $\mathrm{I}-131^{17}, f$ is the equivalent thyroid dose coefficient ${ }^{16,17}$, and $i$ is the thyroid uptake factor equal to 0.3 . The effective half-lives of 3 months (from 0 to 1 year of age), 5 years (more than 2 to 7 years of age), 15 years (more than 12 to 17 years of age), and adult (more than 17 years of age) were calculated using each biological half-life given by ICRP Publication $67^{17}$, and they were estimated to be 4.67, 5.94, 7.15, and 7.27 days, respectively.

Retrospective thyroid equivalent dose by inhalation for young children. In order to estimate the retrospective thyroid dose by inhalation for young children with high risk, we used the maximum atmospheric I-131 concentration estimated from the thyroid activity of evacuees. We calculated the concentration $\left(C_{\mathrm{I}}: \mathrm{Bq} \mathrm{\textrm {m } ^ { - 3 }}\right)$ as the following equation:

$$
C_{\mathrm{I}}=\frac{A_{\mathrm{T}}}{(0.5)^{t / T_{\mathrm{eff}}}} \cdot(V \cdot i)^{-1}
$$

Where $V$ is the breathing volume over 4 hours $\left(\mathrm{m}^{3}\right)$ and we used the typical value at each age given by ICRP Publication $71^{16}$. The maximum concentration $\left(C_{\mathrm{I}-\max }\right)$ among all the examinees was $23 \pm 2 \mathrm{kBq} \mathrm{m}^{-3}$ and we estimated the retrospective thyroid dose $(D: \mathrm{mSv})$ for young children by the following equation:

$$
D=C_{\mathrm{I}-\max } \cdot V \cdot f
$$

1. Sato, M. et al. Displacement above the hypocenter of the 2011 Tohoku-oki earthquake. Science 322, 1395 (2011).

2. Kawagucci, S. et al. Disturbance of deep-sea environments induced by the M9.0 Tohoku earthquake. Sci. Rep. 2, 270; DOI:10.1038/srep00270 (2012).

3. Tanimoto, T., Uchida, N., Kodama, Y., Teshima, T. \& Taniguchi, S. Safety of workers at the Fukushima Daiichi nuclear power plant. Lancet 377, 1489-1490 (2011).

4. Endo, S. et al. Measurement of soil contamination by radionuclides due to the Fukushima Dai-ichi Nuclear Power Plant accident and associated estimated cumulative external dose estimation. J. Environ. Radioact. 111, 18-27 (2012).

5. Zheng, J. et al. Isotopic evidence of plutonium release into the environment from the Fukushima DNPP accident. Sci. Rep. 2, 304; DOI:10.1038/srep00304 (2012).

6. Fukushima Prefectural Government, http://www.pref.fukushima.jp/j/2050km40.pdf (accessed 3 April 2012).

7. Chino, M. et al. Preliminary estimation of release amounts of ${ }^{131} \mathrm{I}$ and ${ }^{137} \mathrm{Cs}$ accidentally discharged from the Fukushima Daiichi Nuclear Power Plant into the atmosphere. J. Nucl. Sci.Technol. 48, 1129-1134 (2011).

8. Katata, G., Terada, H., Nagai, H. \& Chino, M. Numerical reconstruction of high dose rate zones due to the Fukushima Dai-ichi Nuclear Power Plant accident. J. Environ. Radioact. 111, 2-12 (2012). 
9. Hosoda, M. et al. The time variation of dose rate artificially increased by the Fukushima nuclear crisis. Sci. Rep. 1, 87; DOI: 10.1038/srep00087 (2011).

10. Matsumura, H., Saito, K., Ishioka, J. \& Uwamino, Y. Behavior of radioactive materials from Fukushima Daiichi nuclear power station obtained by radiation on the expressways. J. At. Energy. Soc. Jpn. 10, 152-162 (2011).

11. Monzen, S. et al. Individual radiation exposure dose due to support activities at safe shelters in Fukushima prefecture. PLoS ONE 6, e27761; DOI:10.1371/ journal.pone.0027761 (2011)

12. Yoshizawa, Y. \& Kusama, T. Weight, iodine content and iodine uptake of the thyroid gland of normal Japanese. Jpn. J. Health Phys. 11, 123-128 (1976).

13. United Nations Scientific Committee on the Effects of Atomic Radiation. UNSCEAR 2008 report Vol. II. Effects of ionizing radiation. Annex D: Health effects due to radiation from the Chernobyl accident (United Nations, New York, 2011).

14. Akiba, S. Epidemiological studies of Fukushima residents exposed to ionising radiation from the Fukushima Daiichi Nuclear Power Plant prefecture-a preliminary review of current plans. J. Radiol. Prot. 32, 1-10 (2012).

15. Nuclear Safety Commission of Japan, http://www.nsc.go.jp/mext_speedi/0312 0406 _ex.pdf (accessed 3 April 2012).

16. International Commission on Radiological Protection, Age-dependent Doses to Members of the Public from Intake of Radionuclides -Part 4 Inhalation Dose Coefficients (ICRP Publication 71. Ann. ICRP.25, 1995).

17. International Commission on Radiological Protection, Age-dependent doses to members of the public from intake of radionuclides - Part 2 Ingestion dose coefficients (ICRP Publication 67. Ann. ICRP. 22, 1992)

18. Covell, D. F. Determination of gamma-ray abundance directly from total absorption peak. Anal. Chem. 31, 1785-1790 (1959).
19. Ishikawa, T. \& Uchiyama, M. Calibration of apparatus for measuring ${ }^{131}$ I thyroid burden, using anthropometric phantoms of different sizes. Jpn. J. Health Phys. 32, 67-70 (1997).

\section{Acknowledgments}

The authors thank Dr. I. Zvonova, Institute of Radiation Hygiene, Mr. K. Matsumaru, Japan Broadcasting Corporation, Prof. Y. Asari, Mr. K. Sasaki and Mr. Y. Kumazawa, Hirosaki University for their kind assistance in carrying out this study. Dr. N. H. Harley assisted in editing the manuscript.

\section{Author contribution statement}

S.T., S.A., and I.K. designed the study; S.T., M.H., S.A. and A.S. performed experiments; S.T, M.H., and M.B. analyzed thyroid dose, S.T., M.H. and S.A. wrote the manuscript; S.T. supervised the study. All authors contributed extensively to discussions about this work and in reviewing the manuscript.

\section{Additional information}

Competing financial interests: The authors declare no competing financial interests.

License: This work is licensed under a Creative Commons

Attribution-NonCommercial-ShareAlike 3.0 Unported License. To view a copy of this license, visit http://creativecommons.org/licenses/by-nc-sa/3.0/

How to cite this article: Tokonami, S. et al. Thyroid doses for evacuees from the Fukushima nuclear accident. Sci. Rep. 2, 507; DOI:10.1038/srep00507 (2012) 